\title{
Cytokine and chemokine expression in cigarette smoke-induced lung injury in guinea pigs
}

\author{
S. Kubo, M. Kobayashi, Y. Masunaga, H. Ishii, Y. Hirano, K. Takahashi and Y. Shimizu
}

ABSTRACT: The guinea pig model of cigarette smoke (CS)-induced lung injury is known to exhibit many pathophysiological similarities to chronic obstructive pulmonary disease (COPD), but the expression profiles of inflammatory mediators in the lung are poorly understood.

Quantitative real-time RT-PCR was used in this study to investigate the pulmonary expression profiles of cytokine and chemokine mRNA in response to single or repeated CS exposure in guinea pigs.

A single CS exposure did not induce obvious inflammatory cell infiltration into the lungs, but it led to significant increases in the mRNA expression of tumour necrosis factor- $\alpha$, interleukin (IL)$1 \beta$, IL-8, and monocyte chemoattractant protein (MCP)-1, and decreases in IL-5 and granulocytemacrophage colony-stimulating factor. Repeated CS exposure induced many features of COPD, such as marked accumulation of macrophages and neutrophils, augmented protease activities, lung structural alterations and increased airway resistance, accompanied by significant increases in the mRNA expression of IL-1 $\beta$ and MCP-1 and decreases in IL-2, IL-5, transforming growth factor- $\beta$, and eotaxin.

In conclusion, in guinea pigs, inflammatory mediator changes in the lungs following cigarette smoke exposure are largely similar to those reported for smokers and/or chronic obstructive pulmonary disease patients. This model will therefore be useful to further understand the pathogenesis of chronic obstructive pulmonary disease.

KEYWORDS: Animal model, chemokines, chronic obstructive pulmonary disease, cigarette smoking, cytokines, gene expression

hronic obstructive pulmonary disease (COPD) is characterised by slowly progressive and largely irreversible airflow limitation due to chronic bronchitis, emphysema, or both. It is currently one of the most common causes of death in Western countries. With the exception of genetic aetiology, including $\alpha 1$ antitrypsin deficiency, chronic pulmonary inflammation caused by long-term cigarette smoking is the most accepted pathogenesis. Inflammatory cells that play central roles in COPD include macrophages, neutrophils, and T-lymphocytes. Various inflammatory mediators derived from these cells, such as cytokines/ chemokines (tumour necrosis factor (TNF)- $\alpha$, interleukin (IL)-8, and monocyte chemoattractant protein (MCP)-1, etc.), lipids (leukotriene B4, etc.), and proteases (matrix metalloproteinase (MMP)2,8 , and 9 , etc., which are counteracted by tissue inhibitors of matrix metalloproteinases (TIMPs)), are suggested to contribute to disease development $[1,2]$. However, compared with other diseases of the lung, such as asthma, the detailed pathology of COPD is still relatively unknown.

Previous studies have demonstrated the possible induction of COPD-like lung injuries, by exposure to lipopolysaccharides, ozone, nitrogen dioxide, sulphur dioxide, cigarette smoke (CS), or other environmental pollutants, in several animal species [3-7]. Among them, guinea pig CS models are considered to be adequate for further investigations of COPD because of the anatomical and pathophysiological similarities to human COPD [6]. It is generally accepted that shortterm CS exposure causes increased pulmonary permeability and accumulation of inflammatory cells [6, 8-12], and long-term exposure causes emphysematous airspace enlargement in the guinea pig models [12-15]. The guinea pig CS models have contributed to the current understanding of histological and physiological aspects of smoke-associated lung disease, but the underlying molecular mechanisms, including local

\section{AFFILIATIONS}

Inflammation Research,

Pharmacology Laboratories, Institute for Drug Discovery Research,

Yamanouchi Pharmaceutical Co. Ltd, Ibaraki, Japan.

CORRESPONDENCE

S. Kubo

Inflammation Research

Pharmacology Laboratories

Institute for Drug Discovery Research Yamanouchi Pharmaceutical Co. Ltd

21, Miyukigaoka

Tsukuba-shi

Ibaraki 305-8585

Japan

Fax: 81663045367

E-mail:

satoshi.kubo@jp.astellas.com

Received

April 102005

Accepted after revision:

August 142005 
production of cytokines and chemokines, are poorly understood because of the limited availability of research tools, such as specific antibodies for guinea pig proteins.

In this study, quantitative real-time RT-PCR technology was used to investigate the gene expression patterns of cytokines (TNF- $\alpha$, IL-1 $\beta$, IL-2, IL-5, granulocyte-macrophage colonystimulating factor (GM-CSF) and transforming growth factor (TGF)- $\beta$ ) and chemokines (IL-8, MCP-1 and eotaxin) in both the acute and chronic phases of a guinea pig CS model. Pathological and physiological analyses were also performed for this model to investigate the relationship between those cytokine and chemokine expression patterns and the diseased states.

\section{MATERIALS AND METHODS \\ Animals}

Male Hartley strain guinea pigs were purchased from SLC (Shizuoka, Japan). The animals were maintained in ordinary animal cages, with food and water available ad libitum. Animals that were 7 weeks old and weighed 400-600 $\mathrm{g}$ at the start of the experiments were used. Experiments were performed in accordance with the regulations of the Animal Ethical Committee of Yamanouchi Pharmaceutical.

\section{Study design}

Acute phase model

Animals were singly exposed to CS. A bronchoalveolar lavage (BAL) was performed 3, 24, or $48 \mathrm{~h}$ after the exposure. Lung extraction for mRNA expression analysis was performed $2-3 \mathrm{~h}$ after exposure, in separate animals.

\section{Chronic phase model}

Animals were repeatedly exposed to CS for 4 weeks. Body weight or airway resistance was measured twice or once a week, respectively, for the duration of the experiment. BAL and lung extraction for mRNA expression and histopathological analyses were performed $2-3 \mathrm{~h}$ after the last exposure. The lung extraction was performed in separate animals. Detailed methods are described below. For all studies, the numbers of animals are indicated in the figure legends.

\section{Cigarette smoke exposure}

CS exposure was conducted using a set of CS generator SG-200 and inhalation apparatus made up of 20 chambers (Sibata Scientific Technology Ltd, Tokyo, Japan). A commercially available nonfilter cigarette was used (Peace brand cigarettes; Japan Tobacco Inc., Tokyo, Japan) and, according to the manufacturer's specifications, each cigarette contained $2.4 \mathrm{mg}$ of nicotine and $24 \mathrm{mg}$ of tar. Referring to previous studies [8$14]$, the smoking conditions used in this study were determined based on the levels of BAL fluid (BALF) protein and total cell count. Each animal was placed into an individual chamber and exposed to diluted CS in a conscious and restrained state. In the acute phase experiment, animals were exposed to the smoke of a total of 10 cigarettes during a 40-min period. Each cigarette was puffed 15 times for $3 \mathrm{~min}$ at a rate of 5 puffs $\cdot \mathrm{min}^{-1}$. One puff meant drawing $35 \mathrm{~mL}$ of $\mathrm{CS}$ into a $50 \mathrm{~mL}$ syringe, and then blowing this CS, which was diluted to $4-5 \%$ with air, into the apparatus. Fresh air inhalation was performed for $1 \mathrm{~min}$ after every $3 \mathrm{~min}$ of CS exposure. In the chronic phase experiment, animals were repeatedly exposed to the smoke of 10 cigarettes $\cdot$ day $^{-1}, 5$ consecutive days. $^{-1}$ week $^{-1}$, for 4 weeks under the same conditions as described above. Animals placed into the same type of apparatus and exposed to fresh air instead of CS were used as the fresh air control.

\section{Histopathological evaluation}

In the chronic model, animals were sacrificed 2-3 $\mathrm{h}$ after the last exposure, the lungs were then removed and fixed in $10 \%$ neutral-buffered formalin, embedded in paraffin, sectioned at $2 \mu \mathrm{m}$, and stained with haematoxylin and eosin. Histopathological assessment in the bronchus and the parenchyma was performed in a blind fashion.

\section{Measurement of airway resistance}

In the chronic model, at $2-4 \mathrm{~h}$ after CS exposure, specific airway resistance (sRaw) was measured using a twochambered double-flow plethysmograph [16]. In brief, a conscious animal was placed with its neck extending through the partition of a two-chambered box, and sRaw was measured using a noninvasive airway mechanics analyser (BioSystem XA software; Buxco Electronics, Sharon, CT, USA). A bias flow of air $\left(25 \mathrm{~mL} \cdot \mathrm{s}^{-1}\right)$ was maintained through the nasal chamber to ensure a constant supply of fresh air to the animal. sRaw data were logged at 5-s intervals; the mean of 12 consecutive interval averages was calculated as the measurement for time point.

\section{Brochoalveolar lavage}

The guinea pigs were sacrificed under urethane anaesthesia $\left(1.2 \mathrm{~g} \cdot \mathrm{kg}^{-1}\right.$ i.p. $)$, after which their tracheas were cannulated. The lungs were lavaged with $5 \mathrm{~mL}$ of ice-cold saline containing heparin $\left(1 \mathrm{U} \cdot \mathrm{mL}^{-1}\right)$ five times via the cannula. Heparinised saline was used to prevent the coagulation of recovered cells. The BALF was centrifuged at $400 \times g$ for $10 \mathrm{~min}$ at $4{ }^{\circ} \mathrm{C}$. The cell pellet was resuspended in $2 \mathrm{~mL}$ of ice-cold heparinised saline for measuring the total cell count, and the supernatant was stored at $-80^{\circ} \mathrm{C}$ until used. BAL was performed 3,24 and $48 \mathrm{~h}$ after CS exposure in the acute experiment and 2-3 $\mathrm{h}$ after the last exposure in the chronic experiment. The total number of leukocytes in the BALF was counted using an automated cell counter (Celltac- $\alpha$; Nihon Kohden, Tokyo, Japan). The differential cell count was performed using a cytospin preparation stained with Diff-Quik (International Reagent Corp., Kobe, Japan). A minimum of 300 cells were identified and differentiated as mononuclear cells, neutrophils or eosinophils using the standard morphological criteria. The total protein content in the BALF supernatant was measured using a protein assay kit (Bio-Rad Laboratories, Hercules, CA, USA).

\section{Extraction of total RNA}

The lungs were removed 2-3 h after CS exposure in both the acute and chronic experiments. Total RNA was extracted from the lung with ISOGEN reagent (Nippon Gene, Tokyo, Japan) according to the manufacturer's instructions. The amount of extracted RNA was quantified by measuring the absorbance at $260 \mathrm{~nm}$.

\section{Measurement of cytokine and chemokine mRNA expression using quantitative RT-PCR}

The cytokines and chemokines that were analysed in this study were selected based on the following reasons: 1) they were 
implicated in inflammatory conditions such as COPD and asthma; and 2) their sequences in guinea pigs were already published. PCR primers and TaqMan ${ }^{\circledR}$ probes were designed using Primer Express 1.5 Software (Applied Biosystems, Foster City, CA, USA) based on the sequence entries in GenBank. The sequences of primers and probes used in this experiment are summarised in table 1 . All primers and probes were obtained from Proligo Japan (Kyoto, Japan). In this study, the sequence of guinea pig neutrophil attractant protein-1 was used as IL-8, as described in a previous report [10]. RT-PCR was performed using the ABI PRISM 7700 sequence detection system (Applied Biosystems) with a one-step RT-PCR kit (TaqMan ${ }_{\circledast}$ EZ RT-PCR Core Reagents; Applied Biosystems) in accordance with the manufacturer's instructions. In brief, final concentrations used in the $25 \mu \mathrm{L}$ reaction mix were: $50 \mathrm{ng}$ (glyceraldehyde-3phosphate dehydrogenase (GAPDH), IL-1 $\beta$, IL-2, IL-5, eotaxin, GM-CSF and TGF- $\beta$ ) or 500 ng (TNF- $\alpha$, IL-8 and MCP-1) of total RNA; $200 \mathrm{nM}$ of each primer; $100 \mathrm{nM}$ of probe; $2.5 \mathrm{U}$ rTth enzyme; $300 \mu \mathrm{M}$ deoxynucleotide triphosphates; $3 \mathrm{mM}$ manganese acetate; and $1 \times \mathrm{EZ}$ buffer. Thermal cycling conditions were as follows: $55^{\circ} \mathrm{C}$ for $50 \mathrm{~min}, 60^{\circ} \mathrm{C}$ for $10 \mathrm{~min}$, and $95^{\circ} \mathrm{C}$ for
2 min, followed by 40 cycles of $95^{\circ} \mathrm{C}$ for $20 \mathrm{~s}$ and $58^{\circ} \mathrm{C}$ for $90 \mathrm{~s}$. The expression levels of each gene were normalised to GAPDH levels and displayed as the fold change relative to normal or fresh air controls.

\section{Gelatin zymography}

The BALF supernatants were concentrated five-fold with Centricon YM-3 filters (Millipore Corp., Bedford, MA, USA). The concentrated samples and positive controls (purified human MMP-2 and -9; Chemicon, Temecula, CA, USA) were loaded onto $8 \%$ sodium dodecyl sulfate (SDS)-polyacrylamide gels containing $1 \mathrm{mg} \cdot \mathrm{mL}^{-1}$ gelatin under nonreducing conditions. After electrophoresis, the gel was washed in $50 \mathrm{mM}$ Tris$\mathrm{HCl}(\mathrm{pH} 7.5$ ) containing $0.1 \mathrm{M} \mathrm{NaCl}$ and $2.5 \%$ Triton $\mathrm{X}-100$ for $2 \mathrm{~h}$ to remove the SDS. The gel was then rinsed in water and incubated overnight at $37^{\circ} \mathrm{C}$ in development buffer, $50 \mathrm{mM}$ Tris- $\mathrm{HCl}(\mathrm{pH} 7.5)$ and $20 \mathrm{mM} \mathrm{CaCl}$. After development, the gel was stained with staining solution, $0.25 \%$ Coomassie blue $\mathrm{R} 250$ in $45 \%$ methanol $/ 10 \%$ acetic acid $/ 45 \% \mathrm{H}_{2} \mathrm{O}$, and subsequently washed with destaining solution, $30 \%$ methanol $/ 10 \%$ acetic acid $/ 60 \% \mathrm{H}_{2} \mathrm{O}$. Gelatinolytic activities were

TABLE 1 Oligonucleotides for real-time RT-PCR

\begin{tabular}{|c|c|c|c|c|}
\hline mRNA targets & Accession number & & Oligonucleotides $5^{\prime}-3^{\prime}$ & Product size bp \\
\hline \multirow[t]{2}{*}{ GAPDH } & U51572 & $\mathrm{F}$ & CCGGCCAAATACGATGACAT & 76 \\
\hline & & P & 6Fam-AAGAAGGTGGTGAAGCAGGCATCAGAGG-Tamra-p & \\
\hline \multirow[t]{2}{*}{ TNF- $\alpha$} & U77036 & $\mathrm{F}$ & СGTCTCTCСАTССАТСССТTCT & 105 \\
\hline & & $\mathrm{R}$ & СССТААТТСССТTТСТGААССА & \\
\hline \multirow{2}{*}{ IL-1 $\beta$} & & $\mathrm{R}$ & CAGGTACAGATTCTTCCCCTTGA & \\
\hline & & $P$ & 6Fam-AGTGATAACAAAATGCCCGTTGCCTTGG-Tamra-p & \\
\hline \multirow[t]{3}{*}{ IL-2 } & AB010093 & $\mathrm{F}$ & CTTGCACTTCTCACGAGCAGT & 62 \\
\hline & & $\mathrm{R}$ & AGTCGGTCCTGTGTTTGCTTT & \\
\hline & & $P$ & 6Fam-CACCTACTTCAAGCTCTC-Tamra-p & \\
\hline \multirow{2}{*}{ GM-CSF } & & $\mathrm{R}$ & GGCTCAAACTGGTCATAGACAACTTC & \\
\hline & & $P$ & 6Fam-CCCGGCTGCTGTGATGAATGAAACA-Tamra-p & \\
\hline \multirow[t]{3}{*}{ TGF- $\beta$} & AF191297 & $\mathrm{F}$ & TGCGAATGCAGAGACTCAAGTT & 78 \\
\hline & & $\mathrm{R}$ & AGCGCCAGGAATTGTTGCT & \\
\hline & & $P$ & 6Fam-AATGTGGAACAGCACGTGGAACTGTACCA-Tamra-p & \\
\hline \multirow[t]{3}{*}{ IL-8 } & L04986 & $\mathrm{F}$ & CCTTGGATTCCCCTTTATTCCT & 81 \\
\hline & & $\mathrm{R}$ & CGTATGTCCCCATGACATTGTG & \\
\hline & & $P$ & 6Fam-CCTCACAAGAAAAAGCCACCACCTTCC-Tamra-p & \\
\hline \multirow[t]{3}{*}{ MCP-1 } & L04985 & $\mathrm{F}$ & TGTGCTGACCCCACACAGAAGT & 100 \\
\hline & & $\mathrm{R}$ & GCTTTGAAGTTTGAGGTGCAGTTG & \\
\hline & & $P$ & 6Fam-CATTGCCAAACTGGACCAGAGAACCCA-Tamra-p & \\
\hline
\end{tabular}

GAPDH: glyceraldehyde-3-phosphate dehydrogenase; TNF: tumour necrosis factor; IL: interleukin; GM-CSF: granulocyte-macrophage colony-stimulating factor; TGF: transforming growth factor; MCP: monocyte chemoattractant protein; bp: base pairs; F: forward primer; R: reverse primer: P: TaqMan® probe. 
detected as clear bands of gelatin lysis against a blue background stain.

\section{Statistical analysis}

Data were expressed as the means \pm SEM. The statistical significance of differences between groups was determined using unpaired t-tests or one-way ANOVA with Dunnett's multiple range test, and $\mathrm{p}<0.05$ were considered significant.

\section{RESULTS}

A single exposure to cigarette smoke (acute phase model) Analysis of bronchoalveolar lavage fluid

Under the conditions used in this experiment, a single exposure of the guinea pigs to CS (10 cigarettes) caused a significant increase in the BALF protein level, which was detectable $3 \mathrm{~h}$ after exposure and was sustained at the same level for up to $24 \mathrm{~h}$ after (fig. 1a). However, significant changes were not detected in cell number (fig. 1b) or gelatinolytic activity (data not shown) in the BALF of the CS-exposed animals compared with normal control (age-matched untreated) animals at the given time points (3, 24 and $48 \mathrm{~h}$ ). These results indicate that a single exposure to CS can elicit an
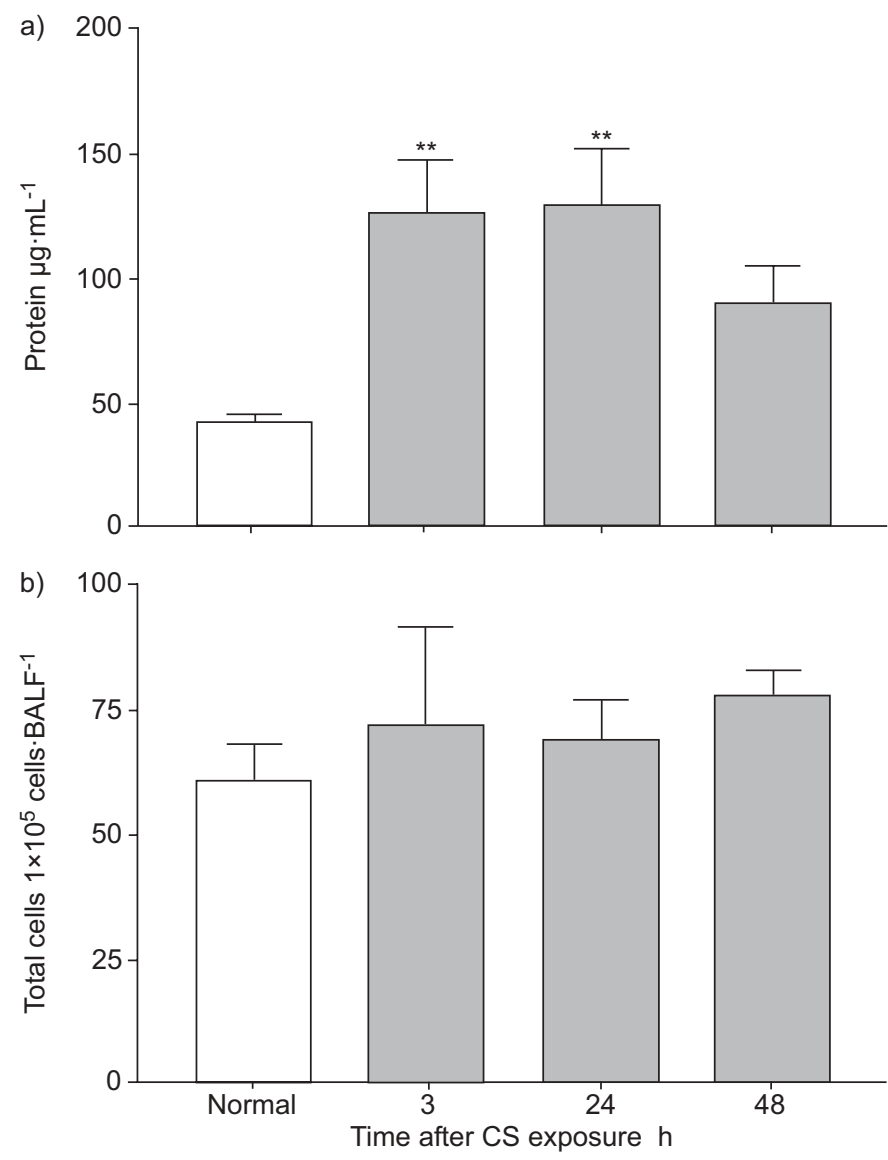

FIGURE 1. Time course of protein concentration and cell counts in bronchoalveolar lavage fluid (BALF) after a single exposure to cigarette smoke (CS). Guinea pigs were singly exposed to CS (10 cigarettes). BAL was performed 3 , 24 or $48 \mathrm{~h}$ after CS exposure. Protein concentration (a) and cell counts (b) in the BALF. The results represent the mean \pm SEM of five animals per group. ${ }^{*}$ : $p<0.01$, significant difference from normal control animals (Dunnett's multiple range test). acute and significant increase of airway permeability without obvious inflammatory cell accumulation in the airways.

Cytokine and chemokine mRNA expression in the lungs of the acute phase model

The sequences of the PCR primers and TaqMan ${ }^{\circledR}$ probes used for the detection of cytokine and chemokine mRNA were all based on previously published guinea pig sequences (table 1). In the lungs harvested from animals 2-3 h after CS exposure, significant increases in the mRNA expression of TNF- $\alpha$ (3.5fold), IL-1 $\beta$ (70-fold), IL-8 (4.0-fold) and MCP-1 (3.4-fold), as well as significant decreases in IL-5 (0.55-fold) and GM-CSF (0.51-fold) were observed compared with normal control animals (fig. 2). Among the nine genes examined, the increase in IL-1 $\beta$ mRNA was the most remarkable. All these alterations of mRNA expressions returned to almost normal levels $24 \mathrm{~h}$ after exposure, except IL-5, which remained at the lower level (data not shown).

\section{Repeated exposure to cigarette smoke (chronic phase model)}

Body weight gain and airway resistance

The body weight of guinea pigs repeatedly exposed to CS

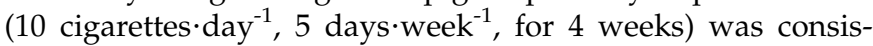
tently lower than that of the fresh air control animals during the experimental period. The average weight of CS-treated animals in the fourth week of exposure was $630 \pm 10.0 \mathrm{~g}$, which was significantly decreased compared with fresh air control animals (664 $\pm 7.1 \mathrm{~g}$; fig. 3a). Since there was no apparent difference in body weight between the fresh air control and the age-matched normal animals (data not shown), restraint stress was deemed to have had no effect on the results.

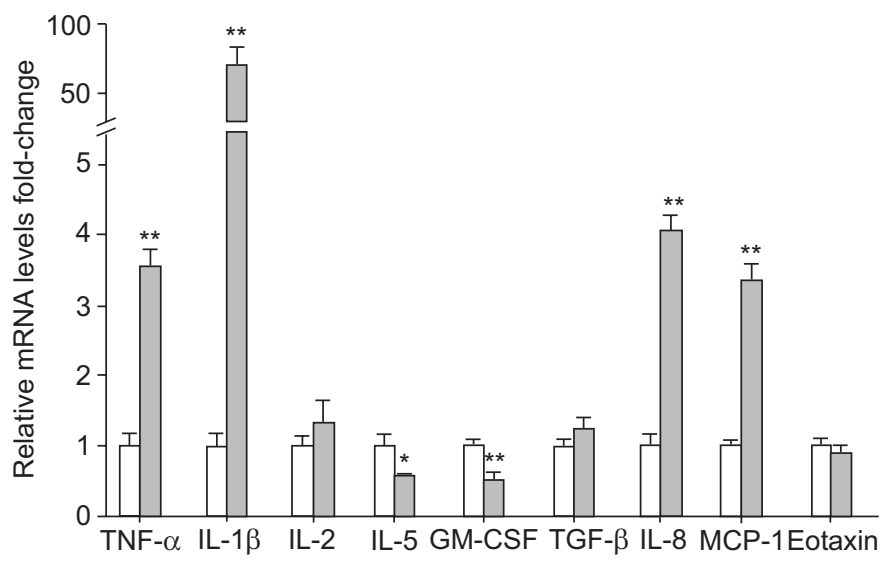

FIGURE 2. Pulmonary gene expression after a single exposure to cigarette smoke (CS). The lungs were removed $2-3 \mathrm{~h}$ after a single CS exposure. Total RNA from the lung was extracted. mRNA encoding the indicated genes were examined using real-time RT-PCR analysis. The expression levels of each gene were normalised to glyceraldehyde-3-phosphate dehydrogenase (GAPDH) expression levels and reported as fold-change relative to normal control animals. The results represent the mean \pm SEM of five animals per group. $\square$ : single CS; $\square$ : normal. TNF tumour necrosis factor; IL: interleukin; GM-CSF: granulocyte-macrophage colonystimulating factor; TGF: transforming growth factor; MCP: monocyte chemoattractant protein $*: p<0.05 ; * *: p<0.01$, significant difference from normal control animals. 

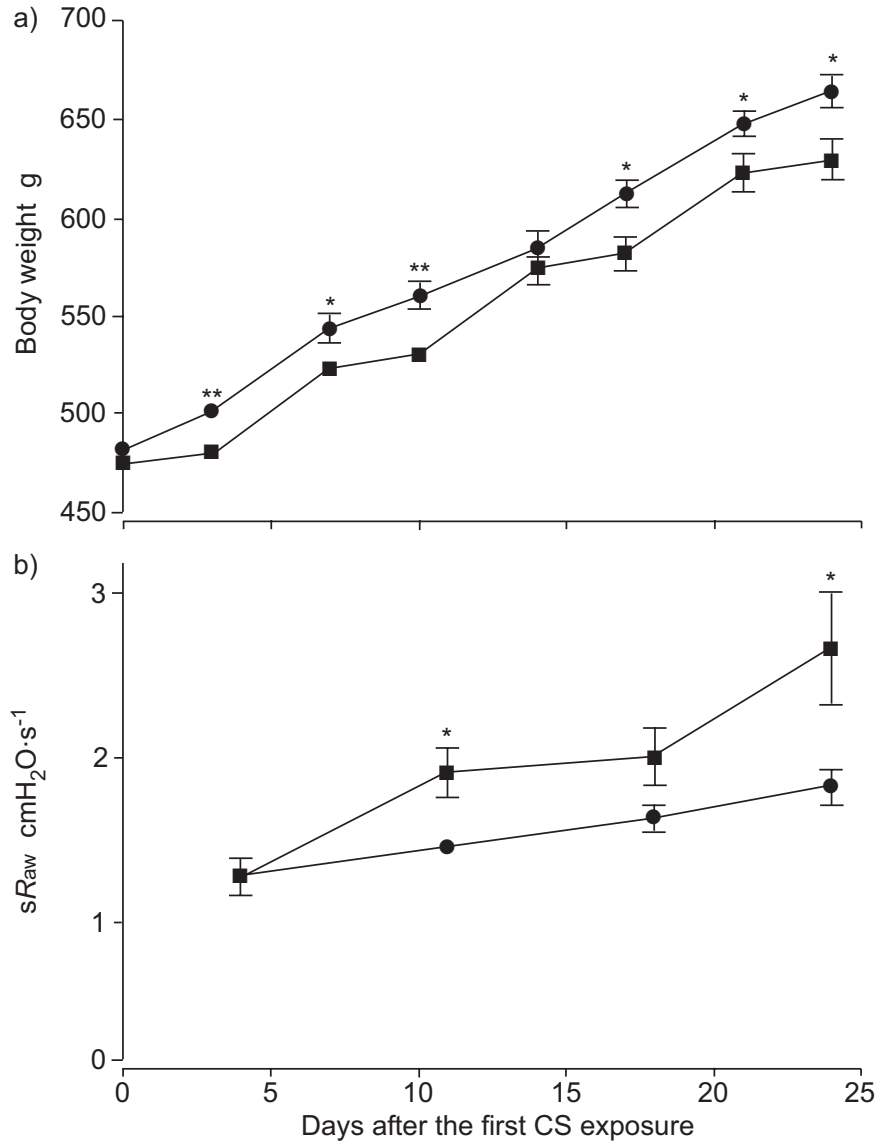

FIGURE 3. Time course of body weight gain and airway resistance in repeated cigarette smoke (CS)-exposed guinea pigs. Guinea pigs were repeatedly exposed to CS (10 cigarettes·day ${ }^{-1}, 5$ days'week ${ }^{-1}$, for 4 weeks). a) Body weight. b) Airway resistance (sRaw). sRaw was assessed in a conscious state at 2-4 $\mathrm{h}$ after CS exposure. The results represent the mean \pm SEM of 9-10 (a) or 6-8 (b) animals per group. $\mathbf{\square}$ : repeated CS; $\bullet$ : fresh air. ${ }^{*}: p<0.05 ;{ }^{*}: p<0.01$, significant difference from fresh air-exposed control animals.

The basal level of airway resistance was measured with a whole-body, double-chamber plethysmograph in a conscious and restrained state. In animals repeatedly exposed to CS, airway resistance did not change during the first week (after 4 consecutive days) of CS exposure, which would have been similar to the acute phase model. However, the airway resistance in animals repeatedly exposed to CS was slightly, but significantly, elevated compared with the control animals in weeks 2 and 4 of exposure (fig. 3b).

\section{Histological evaluation}

In the lungs from guinea pigs repeatedly exposed to CS for 4 weeks, the epithelium of the bronchus showed desquamative and squamous metaplastic changes (fig. 4a versus b). In addition, the alveolar walls of the lungs collected from CS-exposed animals were mildly thickened. Marked infiltration of macrophages into the alveoli and neutrophils into the alveoli and small airways were also noted. The control animals showed none of these signs (fig. 4c versus d). Emphysematous changes, which are characterised by obvious enlargement of the alveolar space, did not develop during the 4-week treatment.

\section{Analysis of bronchoalveolar lavage fluid}

The repeated exposure of guinea pigs to CS for 4 weeks caused a significant increase in the BALF protein level (fig. 5a). Differing from the single exposure model, the repeated CS exposure also induced a marked increase in the cell counts in the BALF compared with the control animals. Differential cell count analysis revealed that the increased cells were composed mainly of mononuclear cells (especially macrophages) and a small amount of neutrophils, but not eosinophils (fig. 5b). The BALF supernatants from animals repeatedly exposed to CS exhibited gelatinolytic activity in the bands of 92 and $220 \mathrm{kD}$, which were regarded as MMP-9 and the homodimer [17], but no such activity was observed in the BALF from control animals. In contrast, the $72 \mathrm{kD}$ bands, which were regarded as MMP-2, were observed at the same levels in the BALF of the repeated CS-exposed and the control animals (fig. 5c).

\section{Cytokine and chemokine mRNA expression in the lungs of the} chronic phase model

In the lungs from guinea pigs $2-3 \mathrm{~h}$ after the last exposure, significant increases in the mRNA expression of IL-1 $\beta$ (6.4fold) and MCP-1 (2.7-fold) were observed compared with the control animals. Although not statistically significant, the level of IL-8 in repeated CS-exposed animals showed a tendency to increase (1.7-fold, $p=0.12)$. Unlike in the acute phase, there was no difference in the level of TNF- $\alpha$ between the CS-exposed and the control groups. In addition, significant decreases in the mRNA expression of IL-2 (0.57-fold), IL-5 (0.47-fold), TGF- $\beta$ (0.68-fold) and eotaxin (0.27-fold) were also observed in the diseased lungs (fig. 6). The decreased mRNA levels of IL-2, TGF- $\beta$ and eotaxin were characteristic events observed only in the chronic phase.

\section{DISCUSSION}

The guinea pig model of CS-induced lung injury is a welldefined COPD model. Previous studies using this model have provided much valuable information on the histological and physiological aspects of smoke-associated lung disease. However, except for an acute exposure study that included IL-8 [10], the pulmonary mRNA expression levels of inflammatory mediators in this model have not been reported. In this study, the pulmonary expression profiles of cytokines and chemokines in response to acute and chronic CS exposure was comprehensively investigated.

Under the current study's experimental conditions, a single CS exposure induced a significant increase in the BALF protein level, but obvious increased numbers of the BALF total cells or neutrophils (data not shown), which had been reported previously [9, 10, 12], were not apparent. However, in some animals, increased myeloperoxidase activities in the BALF could be detected (data not shown), which is a sensitive neutrophil marker. These results suggest that mild neutrophil infiltration, which could not significantly affect the BALF total cell counts, was induced in the current acute phase model. The smoking conditions used in the present study seem to be relatively milder than those described in previous reports.

In this acute phase model, significant increases in the mRNA expression of proinflammatory cytokines and chemokines, e.g. TNF- $\alpha$, IL-1 $\beta$, IL- 8 and MCP-1, in the lung were observed. Among them, the upregulation of IL- $1 \beta$ mRNA (70-fold) was 

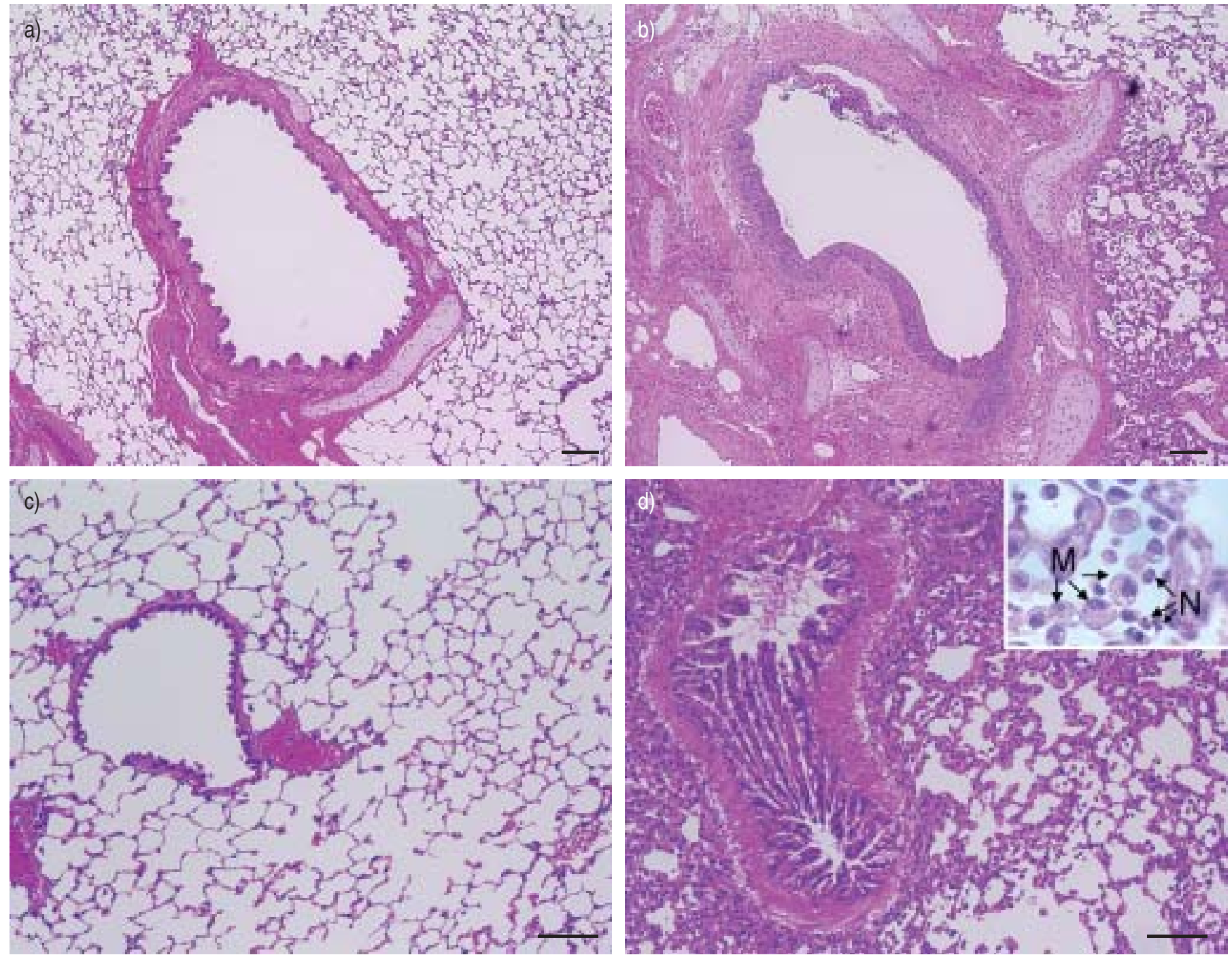

FIGURE 4. Histological views of bronchus and parenchyma sections stained with haematoxylin and eosin. Histological pictures shown are representative of the bronchus ( $a$ and $b$ ) and the parenchyma ( $c$ and d) sections from fresh air-exposed ( $a$ and $c$ ) and repeated cigarette smoke (CS)-exposed (b and d) guinea pigs. The repeated CS exposure induced desquamative and squamous metaplastic changes in the epithelium of the bronchus (b). Mild alveolar wall thickening and marked inflammation in the alveoli and bronchiole were observed in CS-exposed animals (d). A close-up of the alveoli is shown in d). M: macrophages; $\mathrm{N}$ : neutrophils. Scale bar=100 $\mu \mathrm{m}$. The experiment was performed using five animals per group.

especially prominent when compared with those of TNF- $\alpha$, IL8 and MCP-1 mRNA ( $p<0.01$, Dunnett's multiple range test). However, in the chronic phase model, in which many clinical features of COPD were reproduced, the upregulation of IL-1 $\beta$ mRNA (6.4-fold) was not as prominent as observed in the acute phase $(p<0.01)$. These results seem to correlate well with the IL-1 $\beta$ expression levels that were observed in healthy smokers and COPD patients. That is, the concentration of IL-1 $\beta$ is significantly increased in the BALF of healthy smokers compared with nonsmokers [18], whereas there are few reports that suggest the active participation of IL-1 $\beta$ in patients with COPD. Although the importance of IL- $1 \beta$ in COPD is still unknown, IL-1 $\beta$ has been shown to mediate trafficking of inflammatory cells to airway epithelial cells through the upregulation of adhesion molecules such as intercellular adhesion molecule (ICAM)-1 [19]. Thus, IL-1 $\beta$ may be a crucial cytokine especially in the acute/induction phase of
CS-associated lung disease, with the ability to trigger leukocyte trafficking in the lung.

Marked accumulation of macrophages and neutrophils in various parts of the lung is one of the most remarkable features of COPD, and the levels of MCP-1 and IL-8, which are major chemoattractants for macrophages and neutrophils, respectively, are elevated in the BALF [20], lung biopsy [21] and induced sputum [22] from patients with COPD. In the chronic phase model, an accumulation of macrophages and neutrophils in the lung was observed, as well as a significant elevation of MCP-1 mRNA and an increasing tendency for IL-8 mRNA to be present, which suggested that the chemokine expression patterns are similar to those in human COPD. In addition, the expression patterns of chemokines are well correlated with the selective accumulation of their target cells. 

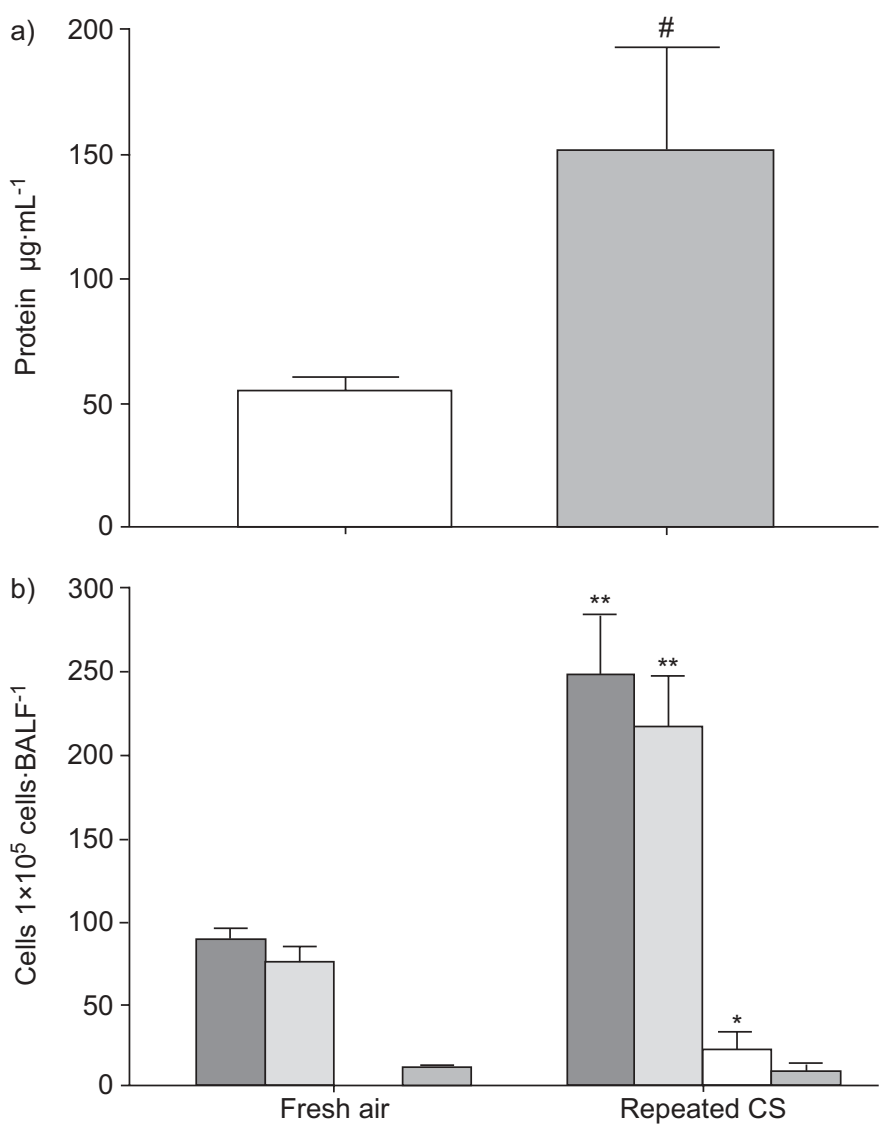

c)

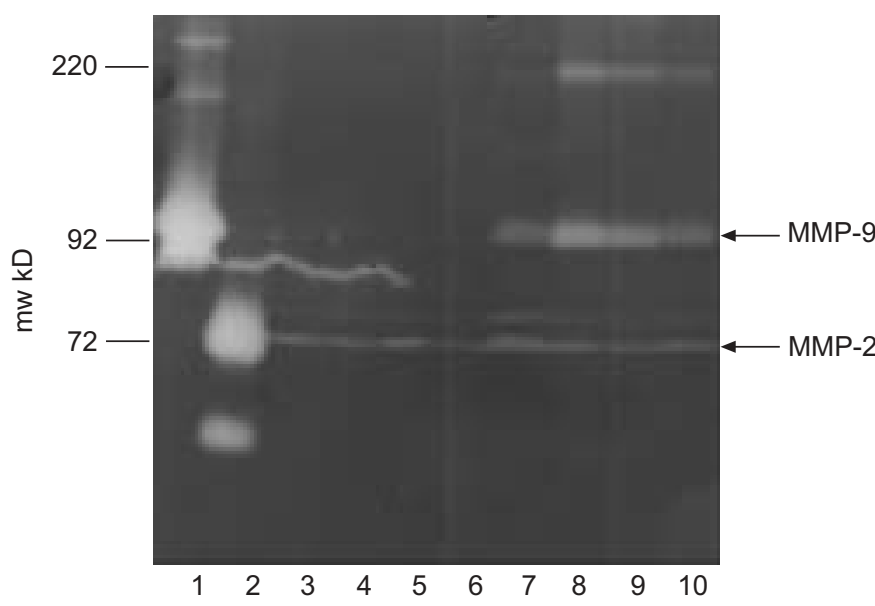

FIGURE 5. Characteristics of the bronchoalveolar lavage fluid (BALF) from repeated cigarette smoke (CS)-exposed guinea pigs. BAL was performed 2-3 h after the last CS exposure. a) Protein concentration and b) cell profiles: total cells $(\square)$; mononuclear cells $(\square)$; neutrophils $(\square)$; eosinophils $(\square)$. Differential cell counts were determined by light microscopy evaluation of cytospin preparations. c) Gelatinolytic activities. These were analysed under nonreducing conditions using gelatin zymography. Human matrix metalloproteinase (MMP)-9 (lane 1); human MMP-2 (lane 2); BALF (lanes 3--6) from fresh air-exposed control animals; BALF from repeated CS-exposed animals (lanes 7-10). The bands of gelatinolytic activities at 72 and $92 \mathrm{kD}$ correspond to MMP-2 and MMP-9, respectively. The results in a) and b) represent the mean \pm SEM of $4-5$ animals per group. ${ }^{*} p=0.052$. $*: p<0.05 ; * *: p<0.01$, significant difference from fresh air-exposed control animals.

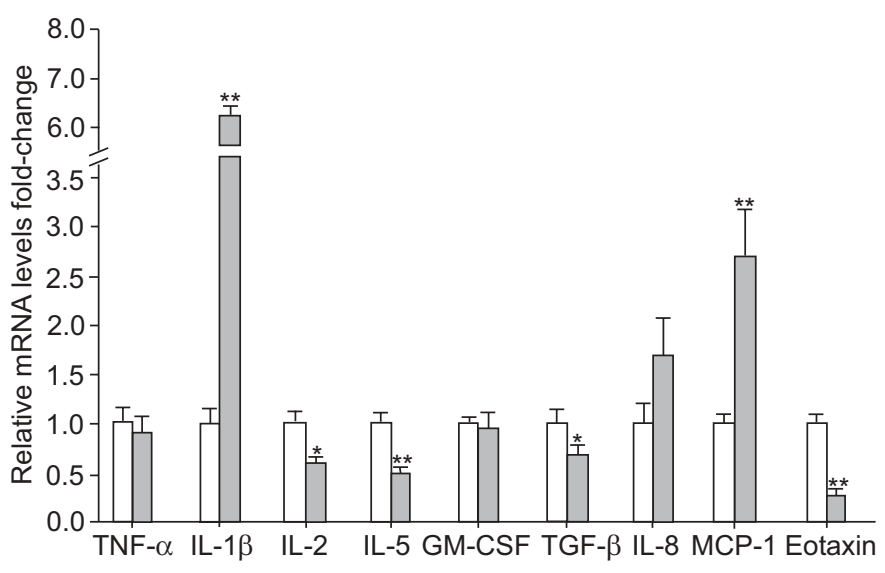

FIGURE 6. Pulmonary gene expression after repeated exposure to cigarette smoke (CS). The lungs were removed 2-3 $\mathrm{h}$ after the last CS exposure. Total RNA from the lung was extracted. mRNA encoding the indicated genes was examined by real-time RT-PCR analysis. The expression levels of each gene were normalised to glyceraldehyde-3-phosphate dehydrogenase (GAPDH) expression levels and reported as fold-change relative to fresh air-exposed control animals. The results represent the mean \pm SEM of 10 or 11 animals per group. $\square$ : fresh air; $\square$ : repeated CS. TNF: tumour necrosis factor; IL: interleukin; GM-CSF: granulocyte-macrophage colony-stimulating factor; TGF: transforming growth factor; MCP: monocyte chemoattractant protein. ${ }^{*}: p<0.05 ;{ }^{*}: p<0.01$, significant difference from fresh air-exposed control animals.

It is noteworthy to mention that a concurrent downregulated expression of IL-5 and eotaxin mRNA was observed in the chronic phase. IL-5 and eotaxin have both been shown to be important in the differentiation, maturation and activation of eosinophils [23, 24]. In contrast to asthma, eosinophils do not seem to be prominent in COPD, except during exacerbation or when patients have concomitant asthma [2]. Consistent with this, eosinophilia was not observed in this nonasthmatic chronic CS model.

In the chronic phase, a decreased level of IL-2 mRNA was also observed. IL-2 is produced primarily by T-cells, especially activated CD4+ T-cells, and plays important roles in regulating T-cell functions [25]. Previously, Hagiwara et al. [26] had demonstrated that there were no cells spontaneously secreting IL-2 in the BALF of smokers, whereas most nonsmokers had detectable IL-2-secreting cells. They suggested that cigarette smoking can disturb the T-cell immune balance, which may explain the susceptibility of smokers to certain airway disease conditions such as viral or microbial infections. The current results seem to correlate well with these observations in humans.

TNF- $\alpha$ is one of the most extensively studied cytokines in COPD. An increased level of TNF- $\alpha$ has been observed in lung biopsy [27], induced sputum [22] and serum [28] from patients with COPD. Although TNF- $\alpha$ elevation in plasma has been reported in a previous guinea pig CS study [12], expression profiles in the lung have not been demonstrated. In the present guinea pig model, a significant increase of TNF- $\alpha$ mRNA was observed in the lung during the acute phase, but not the chronic phase. There is no convincing reason for the lack of elevation in TNF- $\alpha$ levels in the chronic phase. However, SOLER 
et al. [29] reported a positive correlation between TNF- $\alpha$ levels in the BALF and the presence of pathogenic microbial infection in COPD patients. Additionally, there is evidence that the TNF- $\alpha$ level was significantly higher in COPD patients experiencing exacerbation than in stable patients [30]. The specific contribution of TNF- $\alpha$ in the chronic phase model may depend on additional disease conditions.

A significant decrease of GM-CSF mRNA was observed only in the acute phase. At present, it is difficult to explain the physiological implications of this phenomenon because there is no evidence supporting this result.

In the histological examination of the chronic phase model, lung structural alterations, such as desquamative and squamous metaplastic changes of airway epithelium, as well as alveolar wall thickening. These changes are commonly observed characteristics of COPD were observed [31]. However, emphysematous airspace enlargement in the parenchyma was not observed. The most accepted hypothesis for the development of emphysema is the protease-antiprotease imbalance theory [2, 32, 33]. Although no emphysematous lesions were observed, a marked increase of BALF MMP-9 activity could be detected in the chronic phase model. In addition, an increase in MMP-8 mRNA (1.3-fold) and a decrease in TIMP-2 mRNA (0.68-fold) were also observed in this phase (data not shown). These findings indicate that the protease-antiprotease imbalance had already occurred in this 4-week CS exposure model. Furthermore, the mRNA expression of TGF- $\beta$, which is considered to play a protective role in the development of emphysema [34, 35], was significantly decreased in this model. Therefore, the extension of the smoking period would lead to emphysematous pathophysiology, as described in previous reports [12-15].

A decrease of weight gain in the repeated CS-exposed animals was also observed. Although body weight loss is a common feature in COPD patients, its exact mechanism and what role repeated CS exposure plays in it are not known at present.

In summary, this study investigated the pulmonary expression profiles of inflammatory mediators in the acute and chronic phases of the well-defined guinea pig cigarette smoke model using quantitative RT-PCR technology. The current results showed that the guinea pig cigarette smoke model had many similarities to those reported in smokers and/or chronic obstructive pulmonary disease patients not only histologically and physiologically, but also with regard to inflammatory mediator changes. Recently, the number of available DNA sequences for guinea pigs has been rapidly increasing, so more elaborate expression analysis will be useful for further understanding of the complex pathology of chronic obstructive pulmonary disease.

\section{ACKNOWLEDGEMENTS}

The authors would like to thank T. Yamada and J. Ishikawa (Inflammation Research, Pharmacology Laboratories, Institute for Drug Discovery Research, Yamanouchi Pharmaceutical Co., Ltd, Ibaraki, Japan) for their invaluable suggestions and S. Kuromitsu for technical advice with the real-time PCR studies.

\section{REFERENCES}

1 Pauwels RA, Buist AS, Calverley PM, Jenkins CR, Hurd SS. Global strategy for the diagnosis, management, and prevention of chronic obstructive pulmonary disease. NHLBI/WHO Global Initiative for Chronic Obstructive Lung Disease (GOLD) Workshop summary. Am J Respir Crit Care Med 2001; 163: 1256-1276.

2 Barnes PJ. Chronic obstructive pulmonary disease. N Engl J Med 2000; 343: 269-280.

3 Nikula KJ, Green FH. Animal models of chronic bronchitis and their relevance to studies of particle-induced disease. Inhal Toxicol 2000; 12: Suppl. 4, 123-153.

4 March TH, Green FH, Hahn FF, Nikula KJ. Animal models of emphysema and their relevance to studies of particleinduced disease. Inhal Toxicol 2000; 12: Suppl. 4, 155-187.

5 Chitano P, Hosselet JJ, Mapp CE, Fabbri LM. Effect of oxidant air pollutants on the respiratory system: insights from experimental animal research. Eur Respir J 1995; 8: 1357-1371.

6 Wright JL, Churg A. A model of tobacco smoke-induced airflow obstruction in the guinea pig. Chest 2002; 121, Suppl. 5, 188S-191S.

7 Shapiro SD. Animal models for COPD. Chest 2000; 117: Suppl. 5, 223S-227S.

8 Hulbert WC, Walker DC, Jackson A, Hogg JC. Airway permeability to horseradish peroxidase in guinea pigs: the repair phase after injury by cigarette smoke. Am Rev Respir Dis 1981; 123: 320-326.

9 Wright J, Harrison N. Cardiopulmonary effects of a brief exposure to cigarette smoke in the guinea pig. Respiration 1990; 57: 70-76.

10 Nishikawa M, Kakemizu N, Ito $T$, et al. Superoxide mediates cigarette smoke-induced infiltration of neutrophils into the airways through nuclear factor- $\mathrm{BB}$ activation and IL-8 mRNA expression in guinea pigs in vivo. Am J Respir Cell Mol Biol 1999; 20: 189-198.

11 Matsumoto $\mathrm{K}$, Aizawa $\mathrm{H}$, Inoue $\mathrm{H}$, et al. Eosinophilic airway inflammation induced by repeated exposure to cigarette smoke. Eur Respir J 1998; 12: 387-394.

12 Wright JL, Farmer SG, Churg A. Synthetic serine elastase inhibitor reduces cigarette smoke-induced emphysema in guinea pigs. Am J Respir Crit Care Med 2002; 166: 954-960.

13 Wright JL, Churg A. Cigarette smoke causes physiologic and morphologic changes of emphysema in the guinea pig. Am Rev Respir Dis 1990; 142: 1422-1428.

14 Selman M, Montano M, Ramos C, et al. Tobacco smokeinduced lung emphysema in guinea pigs is associated with increased interstitial collagenase. Am J Physiol 1996; 271: L734-743.

15 Meshi B, Vitalis TZ, Ionescu D, et al. Emphysematous lung destruction by cigarette smoke. The effects of latent adenoviral infection on the lung inflammatory response. Am J Respir Cell Mol Biol 2002; 26: 52-57.

16 Pennock BE, Cox CP, Rogers RM, Cain WA, Wells JH. A noninvasive technique for measurement of changes in specific airway resistance. J Appl Physiol 1979; 46: 399-406.

17 Kjeldsen L, Johnsen AH, Sengelov H, Borregaard N. Isolation and primary structure of NGAL, a novel protein associated with human neutrophil gelatinase. J Biol Chem 1993; 268: 10425-10432. 
18 Kuschner WG, D'Alessandro A, Wong H, Blanc PD. Dosedependent cigarette smoking-related inflammatory responses in healthy adults. Eur Respir J 1996; 9: 1989-1994.

19 Tosi MF, Stark JM, Smith CW, Hamedani A, Gruenert DC, Infeld MD. Induction of ICAM-1 expression on human airway epithelial cells by inflammatory cytokines: effects on neutrophil-epithelial cell adhesion. Am J Respir Cell Mol Biol 1992; 7: 214-221.

20 Capelli A, Di Stefano A, Gnemmi I, et al. Increased MCP-1 and MIP-1beta in bronchoalveolar lavage fluid of chronic bronchitics. Eur Respir J 1999; 14: 160-165.

21 De Boer WI, Sont JK, Van Schadewijk A, Stolk J, Van Kreiken JH, Hiemstra PS. Monocyte chemoattractant protein 1 , interleukin 8 , and chronic airway inflammation in COPD. J Pathol 2000; 190: 619-626.

22 Keatings VM, Collins PD, Scott DM, Barnes PJ. Differences in interleukin- 8 and tumor necrosis factor- $\alpha$ in induced sputum from patients with chronic obstructive pulmonary disease or asthma. Am J Respir Crit Care Med 1996; 153: 530-534.

23 Mattes J, Foster PS. Regulation of eosinophil migration and Th2 cell function by IL-5 and eotaxin. Curr Drug Targets Inflamm Allergy 2003; 2: 169-174.

24 Chung KF. Individual cytokines contributing to asthma pathophysiology: valid targets for asthma therapy? Curr Opin Investig Drugs 2003; 4: 1320-1326.

25 Paul WE, Seder RA. Lymphocyte responses and cytokines. Cell 1994; 76: 241-251.

26 Hagiwara E, Takahashi KI, Okubo T, et al. Cigarette smoking depletes cells spontaneously secreting Th1 cytokines in the human airway. Cytokine 2001; 14: 121-126.

27 Mueller R, Chanez P, Campbell AM, Bousquet J, Heusser C, Bullock GR. Different cytokine patterns in bronchial biopsies in asthma and chronic bronchitis. Respir Med 1996; 90: 79-85.

28 Takabatake N, Nakamura $H$, Abe S, et al. The relationship between chronic hypoxemia and activation of the tumor necrosis factor- $\alpha$ system in patients with chronic obstructive pulmonary disease. Am J Respir Crit Care Med 2000; 161: 1179-1184.

29 Soler N, Ewig S, Torres A, Filella X, Gonzalez J, Zaubet A. Airway inflammation and bronchial microbial patterns in patients with stable chronic obstructive pulmonary disease. Eur Respir J 1999; 14: 1015-1022.

30 Calikoglu M, Sahin G, Unlu A, et al. Leptin and TNF-alpha levels in patients with chronic obstructive pulmonary disease and their relationship to nutritional parameters. Respiration 2004; 71: 45-50.

31 Jeffery PK. Remodeling in asthma and chronic obstructive lung disease. Am J Respir Crit Care Med 2001; 164: S28-38.

32 Belvisi MG, Bottomley KM. The role of matrix metalloproteinases (MMPs) in the pathophysiology of chronic obstructive pulmonary disease (COPD): a therapeutic role for inhibitors of MMPs? Inflamm Res 2003; 52: 95-100.

33 Russell RE, Culpitt SV, DeMatos C, et al. Release and activity of matrix metalloproteinase- 9 and tissue inhibitor of metalloproteinase-1 by alveolar macrophages from patients with chronic obstructive pulmonary disease. $A m$ J Respir Cell Mol Biol 2002; 26: 602-609.

34 Morris DG, Huang X, Kaminski N, et al. Loss of integrin $\alpha v \beta 6$-mediated TGF- $\beta$ activation causes Mmp12dependent emphysema. Nature 2003; 422: 169-173.

$35 \mathrm{Wu} \mathrm{L}$, Chau J, Young RP, et al. Transforming growth factor- $\beta 1$ genotype and susceptibility to chronic obstructive pulmonary disease. Thorax 2004; 59: 126-129. 